\title{
EVALUASI KELAYAKAN USAHA SARANG BURUNG WALET DI KECAMATAN TELAGA ANTANG KABUPATEN KOTAWARINGIN TIMUR (Studi Kasus: Usaha Sarang Burung Walet Bapak Suwaji)
}

\author{
EVALUATION OF THE BUSINESS FEASIBILITY OF SWALLOW NEST \\ IN THE TELAGA ANTANG SUBDISTRICT \\ EAST KOTAWARINGIN DISTRICT \\ (Case Study: Sumaji's Swallow Nest Business)
}

\author{
${ }^{1}$ Danny Sumardi, ${ }^{2}$ Pordamantra, ${ }^{3}$ Sunariyo
}

\author{
${ }^{1}$ Alumnus Program Studi Agribisnis Fakultas Pertanian Universitas Palangka Raya \\ ${ }^{2,3}$ Staf Pengajar Program Studi Agribisnis Fakultas Pertanian Universitas Palangka Raya \\ email: pordamantra@gmail.com
}

\begin{abstract}
ABSTRAK
Penelitian ini bertujuan untuk mengevaluasi kelayakan usaha sarang burung walet ditinjau dari aspek finansial. Aspek finansial dianalisis dengan metode Net Present Value, Net B/C Rasio, Internal Rate of Return, Payback Periode, serta Analisis Sensitivitas. Penelitian ini merupakan penelitian kuantitatif. Subjek penelitian ini adalah usaha sarang burung walet Bapak Suwaji dan objek penelitiannya adalah kelayakan usaha sarang burung walet. Metode pengumpulan data menggunakan teknik wawancara dan dokumentasi. Teknis analisis data pada penelitian ini adalah analisis kuantitatif untuk menilai aspek keuangan. Berdasarkan hasil penelitian menunjukkan bahwa ditinjau dari aspek keuangan usaha sarang burung walet Bapak Suwaji layak untuk dijalankan karena nilai NPV > 0, Rp 334.415.629; Net B/C > 1, yaitu 2,19; IRR > i, yaitu 35,18\%; Payback Period sebesar 4,4 tahun (4 tahun 4 bulan). Nilainilai tersebut sesuai dengan kriteria penilaian investasi, sehingga usaha sarang burung walet Bapak Suwaji layak untuk dilaksanakan dan dilanjutkan. Analisis sensitivitas pada usaha sarang burung walet menunjukkan bahwa usaha ini sensitif terhadap perubahan produksi yakni (penurunan produksi sebesar 30\% dan penurunan harga jual sebesar 20\%) karena mengalami penurunan nilai NPV, IRR dan Net B/C yang signifikan. Namun usaha masih layak untuk dijalankan.
\end{abstract}

Kata Kunci: Aspek finansial, kelayakan usaha, kriteria investasi, usaha sarang walet

\section{ABSTRACT}

This study aims to evaluate the feasibility of swallow nest business in terms of financial aspects. Financial aspects ware analyzed using the methods of Net Present Value, Net B / C Ratio, Internal Rate of Return, Payback Period, and Sensitivity Analysis. This research is quantitative research. The subject of this research was the swallow nest business of Mr. Suwaji and the object of his research was the feasibility of a swallow nest business. Methods of collecting data using interview techniques and documentation. The data analysis technique of this research is quantitative analysis to assess financial aspects. Based on the results of the study showed that in terms of the financial aspects, the swallow nest business of $\mathrm{Mr}$. Suwajiwas feasible to run because the value of NPV > 0, Rp 334.415.629; Net B/C > 1 which is 2,19; IRR > i, which is 35,18\%; Payback Period is 4,4 years (4 years 4 month). These 
values are in accordance with the investment assessment criteria, so that Mr. Suwaji's swallow nest business is feasible to carry out and continue. Sensitivity analysis in swallow nest business shows that this businessis sensitive to production changes, namely (a decrease in production by $30 \%$ and a decrease in selling price by 20\%) because it has a significant decrease in the value of NPV, IRR, and Net B / C. But the business is still feasible to run.

Keywords: Business feasibility, financial aspects, investment criteria, swallow nest business

\section{PENDAHULUAN}

Sarang walet merupakan hasil dari air liur burung walet yang saat ini memiliki nilai ekonomis yang tinggi oleh karenanya dibudidayakan. Namun setiap usaha termasuk usaha ternak sarang burung walet tentunya tidak terlepas dari berbagai resiko khususnya dalam hal resiko keuangan meskipun jumlah produksinya cukup tinggi. Oleh karena itu, peternak sarang burung walet harus memiliki gambaran tentang evaluasi kelayakan usaha yang dijalankan, tidak hanya terbatas pada bagaimana memelihara dan membudidayakan burung walet hingga menghasilkan sarang sebagai hasil utama produksi (Whiendrata, 2011).

Harga sarang burung walet cukup menggiurkan, sehingga banyak investor atau pemilik modal membangun rumahrumah budidaya sarang burung walet ini. Ada sebagian yang berhasil menjadi pengusaha atau pembudidaya sarang burung walet ini, dan tidak sedikit pula yang gagal dalam bisnis ini. Modal yang sangat besar dengan resiko yang besar, tentunya akan sebanding dengan apa yang telah dikeluarkan. Maka dari itu, mengapa harga sarang burung walet begitu mahal. Jauh sebelum adanya sarang burung walet hasil budidaya rumahan, harga sarang burung walet mencapai 10 juta sampai harga 15 juta rupiah per kilogramnya. Namun setelah banyaknya dibangun rumah budidaya sarang burung walet, harga sarang burung goa pun ikut bersaing, tetapi harga sarang burung goa tetaplah menjadi yang tertinggi (Budiman, 2007).

Proyek merupakan suatu kegiatan yang mengeluarkan uang atau biaya-biaya dengan harapan akan memperoleh hasil dan secara logika merupakan wadah untuk melakukan kegiatan-kegiatan perencanaan, pembiayaan serta pelaksanaan dalam satu unit (Gittinger, 1986).

Evaluasi proyek membahas mengenai kelayakan suatu proyek (gagasan usaha) yang dilihat dari pengusaha secara individu serta dampaknya terhadap masyarakat secara keseluruhan. Evaluasi proyek dapat juga digunakan untuk menilai dan memilih dari bermacam-macam investasi yang mungkin untuk dikembangkan sesuai dengan kemampuan investasi pengusaha (Ibrahim, 2003).

Terdapat beberapa lokasi sentra walet di Indonesia diantaranya di Pulau Sumatera dan Kalimantan. Di pulau Sumatera, sentra walet terdapat di Provinsi Bangka Belitung dan Lampung, sedangkan di Pulau Kalimantan terdapat di semua provinsi kecuali Kalimantan Timur (Budiman, 2008).

Proyek bisnis dapat dikatakan sehat apabila dapat memberikan keuntungan yang layak dan mampu memenuhi kewajiban finansialnya (Umar, 2009).

Salah satu sentra produksi walet di Kalimantan adalah di Provinsi Kalimantan Tengah. Di Kalimantan Tengah, lokasi sentra produksi walet terdapat di Kota Palangka Raya, Sampit, Samuda, dan Pangkalan Bun. Sampit dan Samuda termasuk dalam Kabupaten Kotawaringin Timur.

Berdasarkan data yang diperoleh dari Dinas Penanaman Modal dan Pelayanan Terbuka Satu Pintu (DPMPTSP) Kabupaten Kotawaringin Timur, ada sebanyak 1.190 bangunan yang telah terdaftar dan hanya 347 bangunan saja yang memiliki izin usaha. Salah satu usaha 
burung walet yang telah memiliki izin adalah milik Bapak Suwaji.

Berdasarkan informasi yang diperoleh dari para pengepul, usaha milik Bapak Suwaji ini merupakan usaha yang produksinya tinggi. Harga sarang burung walet di Kecamatan Telaga Antang Kabupaten Kotawaringin Timur dalam bentuk patahan dihargai $\mathrm{Rp} 14$ juta/kg, sarang sudut $\mathrm{Rp} 12 \mathrm{juta} / \mathrm{kg}$, dan sarang mangkuk Rp 11 juta/kg. Melihat besarnya hasil yang diperoleh dari usaha sarang burung walet, peneliti ingin melihat sejauh mana investasi usaha ini kedepannya.

Usaha sarang burung walet ini memiliki harga jual sarang yang tinggi sehingga menarik minat masyarakat untuk ikut menjalani usaha ini namun dalam usaha sarang burung walet ini juga memiliki resiko yang besar. Ketidakstabilan produksi sarang dan harga jual juga berpengaruh terhadap usaha sarang burung walet.

Berdasarkan uraian pada latar belakang, maka penelitian ini bertujuan untuk mengevaluasi kelayakan usaha sarang burung walet dan mengevaluasi tingkat kepekaan (sensitivitas) pada usaha sarang burung walet Bapak Suwaji, apabila terjadi perubahan produksi dan harga jual sarang burung walet.

\section{METODE PENELITIAN}

Penelitian ini merupakan penelitian studi kasus yang dilakukan pada usaha sarang burung walet milik Bapak Suwaji di Kecamatan Telaga Antang, Kabupaten Kotawaringin Timur. Pemilihan lokasi penelitian dilakukan secara sengaja (purposive) dengan pertimbangan bahwa usaha sarang burung walet Bapak Suwaji ini telah berjalan selama 5 tahun dan merupakan salah satu usaha sarang burung walet yang berhasil karena hasil produksinya yang tinggi dan langsung dijual ke pengepul besar. Penelitian ini dilakukan selama tiga bulan, yakni pada bulan Juli hingga September 2018.
Data yang digunakan dalam penelitian ini ada dua jenis, yaitu data primer dan data sekunder. Data primer diperoleh melalui hasil wawancara dengan pihak terkait yakni Bapak Suwaji berupa data teknis dan non teknis usaha, komponen biaya investasi, dan harga jual sarang burung walet, sedangkan data sekunder diperoleh dari laporan keuangan Bapak Suwaji yaitu data penjualan serta gambaran umum usaha Bapak Suwaji. Data sekunder lainnya diperoleh dari literatur yang berkaitan dengan penelitian ini.

\section{a. Cash Flow Analysis}

Biaya Total (Total Cost)

$$
\mathrm{TC}=\mathrm{FC}+\mathrm{VC}+\text { Initial Investment }
$$

Penerimaan Total (Total Revenue)

$$
\mathrm{TR}=\mathrm{Pq} \cdot \mathrm{Q}
$$

Keuntungan (Profit)

Keterangan:

$$
\pi=\mathrm{TR}-\mathrm{TC}
$$

$\mathrm{TR}=$ Total penerimaan

$\mathrm{Q}=$ Jumlah output

$\mathrm{Pq}=$ Harga output

$\mathrm{TC}=$ Total biaya

$\mathrm{FC}=$ Fixed cost

$\mathrm{VC}=$ Variabel cost

$\pi=$ Keuntungan

\section{b. Net Present Value (NPV)}

Secara matematis, NPV dapat dirumuskan sebagai berikut:

$$
\begin{gathered}
N \quad=\sum_{t=0}^{n} \frac{B}{(1+i)^{t}} \\
-\sum_{t=0}^{n} \frac{C}{(1+i)^{t}} \\
=\sum_{t=0}^{n} \frac{B-C}{(1+i)^{t}}
\end{gathered}
$$

Keterangan:

$\mathrm{NPV}=$ Net Present Value 
$\mathrm{Bt}=$ Benefit (penerimaan) bersih tahun ke-t

$\mathrm{C}_{\mathrm{t}}=\operatorname{Cost}$ (biaya) pada tahun ke-t

$\mathrm{t} \quad=$ Tahun (5 tahun)

$\mathrm{i} \quad=$ Tingkat suku bunga yang berlaku $(10 \%)$

$\mathrm{n} \quad=$ Lamanya periode waktu

Kriteria:

Apabila NPV > 0, maka usaha sarang burung walet layak untuk diusahakan

Apabila NPV < 0, maka usaha sarang burung walet tidak layak untuk diusahakan Apabila NPV $=0$, maka usaha sarang burung walet dalam keadaan titik impas (BEP)

\section{c. Internal Rate of Return (IRR)}

Secara matematis, IRR dapat dirumuskan sebagai berikut:

$$
\mathrm{IRR}=\mathrm{i}+\frac{\mathrm{NPV}}{\mathrm{NPV}-\mathrm{NPV}}(\mathrm{i}-\mathrm{i})
$$

Keterangan:

$$
\begin{aligned}
\mathrm{IRR}= & \text { Internal Rate of Return } \\
\mathrm{NPV}_{1}= & \mathrm{NPV} \text { yang bernilai positif } \\
\mathrm{NPV}_{2}= & \mathrm{NPV} \text { yang bernilainegatif } \\
\mathrm{i}_{1}= & \text { Tingkat suku bunga saat NPV } \\
& \text { bernilai positif } \\
\mathrm{i}_{2}= & \text { Tingkat suku bunga saat NPV } \\
& \text { bernilai negatif }
\end{aligned}
$$

Kriteria:

Jika IRR > tingkat suku bunga (i), maka usaha sarang burung walet layak untuk diusahakan

Jika IRR < tingkat suku bunga (i), maka usaha sarang burung walet tidak layak untuk diusahakan

Jika IRR = tingkat suku bunga (i), maka usaha sarang burung walet dalam keadaan break event point

\section{d. Net Benefit Cost Rasio (Net B/C Rasio)}

Secara matematis, Net B/C Rasio dapat dirumuskan sebagai berikut:

$$
\operatorname{Net} \frac{B}{C}=\frac{\sum_{t=1}^{\mathrm{L}} \frac{\mathrm{B}-\mathrm{C}}{(1+\mathrm{l})^{\mathrm{L}}}}{\sum_{\mathrm{t}=1}^{\mathrm{u}} \frac{\mathrm{C}-\mathrm{B}}{(1+\mathrm{l})^{\mathrm{L}}}}
$$

Keterangan:

$$
\begin{array}{ll}
\text { Net } \mathrm{B} / \mathrm{C}= & \text { Net Benefit Cost Rasio } \\
\mathrm{Bt} & =\text { Benefit }(\text { penerimaan }) \\
\mathrm{C}_{\mathrm{t}} & =\text { Cost }(\text { biaya) } \\
\mathrm{t} & =\text { Tahun }(5 \text { tahun) } \\
\mathrm{i} & =\text { Tingkat suku bunga yang } \\
& \text { berlaku }(14 \%) \\
\mathrm{n} & =\text { Lamanya periode waktu }
\end{array}
$$

Kriteria:

Jika Net $\mathrm{B} / \mathrm{C}>1$, maka usaha sarang burung walet menguntungkan

Jika Net $\mathrm{B} / \mathrm{C}=1$, maka usaha dikatakan dalam keadaan break even point

Jika Net $\mathrm{B} / \mathrm{C}<1$, maka usaha sarang burung walet tidak menguntungkan

\section{e. Payback Period (PP)}

Secara matematis, PP dapat dirumuskan sebagai berikut:

$$
\mathrm{PP}=\mathrm{n}+\frac{(\mathrm{a}-\mathrm{b})}{(\mathrm{c}-\mathrm{b})} \times 1 \text { Tahun }
$$

Keterangan:

$$
\begin{aligned}
\mathrm{Pp}= & \text { Payback period } \\
\mathrm{n}= & \text { Tahun terakhir dimana arus kas } \\
& \text { masih belum bisa menutupi investasi } \\
& \text { awal } \\
\mathrm{a}= & \text { Jumlah investasi awal } \\
\mathrm{b}= & \text { Jumlah kumulatif arus kas pada } \\
& \text { tahun ke- } \mathrm{n} \\
\mathrm{c}= & \text { Jumlah kumulatif arus kas pada } \\
& \text { tahun ke } \mathrm{n}+1
\end{aligned}
$$

\section{f. Analisis Sensitivitas}

Analisis sensitivitas adalah suatu analisa untuk dapat melihat pengaruhpengaruh yang akan terjadi akibat keadaan yang berubah-ubah (Gittinger 1986).

Perubahan tersebut diantaranya:

- Penurunan produksi sarang burung walet sebesar $30 \%$, dikarenakan faktor cuaca dan musim bertelur sehingga menyebabkan produksi turun. 
- Penurunan harga jual sarang burung walet sebesar 20\%, dikarenakan penurunan permintaan.

\section{HASIL DAN PEMBAHASAN}

Usaha sarang burung walet Bapak Suwaji berdiri pada tahun 2013 di atas lahan pekarangan rumahnya dengan ukuran gedung 6 x 12 meter (3 lantai). Bapak Suwaji mendapatkan pengetahuan tentang usaha sarang burung walet dari orang lain yang lebih dulu memulai usaha ini.
Lokasi usaha sarang burung walet Bapak Suwaji terletak di Desa Tumbang Sangai, Kecamatan Telaga Antang, Kabupaten Kotawaringin Timur. Lokasi gedung berada tepat di samping rumah pemilik usaha karena lebih aman dan terhindar dari pencuri.

Selengkapnya biaya investasi awal (initial investment), biaya tetap, dan biaya variabel usaha sarang burung walet dapat dilihat pada Tabel 1.

Tabel 1. Proyeksi Arus Kas (dalam ribu Rupiah)

\begin{tabular}{|c|c|c|c|c|c|c|c|}
\hline \multirow{2}{*}{ No. } & \multirow{2}{*}{ Uraian } & \multicolumn{6}{|c|}{ Tahun } \\
\hline & & 0 & 1 & 2 & 3 & 4 & 5 \\
\hline 1. & Arus Masuk & & & & & & \\
\hline & $\begin{array}{l}\text { 1.Total } \\
\text { Penjualan }\end{array}$ & & 6.500 & 104.000 & 208.000 & 208.000 & 260.000 \\
\hline & $\begin{array}{l}\text { 2. Nilai Sisa } \\
\text { Proyek }\end{array}$ & & & & & & 176.649 \\
\hline & $\begin{array}{l}\text { Total Arus } \\
\text { Masuk }\end{array}$ & & 6.500 & 104.000 & 208.000 & 208.000 & 436.649 \\
\hline & $\begin{array}{l}\text { Arus Masuk } \\
\text { Untuk } \\
\text { Menghitung } \\
\text { IRR }\end{array}$ & - & 6.500 & 104.000 & 208.000 & 208.000 & 436.649 \\
\hline 2. & Arus Keluar & & & & & & \\
\hline & $\begin{array}{l}\text { 1. Biaya } \\
\text { Investasi }\end{array}$ & 275.796 & - & - & - & - & - \\
\hline & $\begin{array}{l}\text { 2. Biaya } \\
\text { Variabel }\end{array}$ & & 3.250 & 4.850 & 6.450 & 6.450 & 7.250 \\
\hline & 3. Biaya Tetap & & 8.000 & 8.000 & 8.000 & 8.000 & 8.000 \\
\hline & $\begin{array}{l}\text { Total Arus } \\
\text { Keluar }\end{array}$ & 275.796 & 11.250 & 12.850 & 14.450 & 14.450 & 15.250 \\
\hline & $\begin{array}{l}\text { Arus Keluar } \\
\text { untuk } \\
\text { menghitung } \\
\text { IRR }\end{array}$ & 275.796 & 11.250 & 12.850 & 14.450 & 14.450 & 15.250 \\
\hline 3. & $\begin{array}{l}\text { Arus Bersih } \\
\text { (NCF) }\end{array}$ & - & -4.750 & 91.150 & 193.550 & 193.550 & 421.399 \\
\hline 4. & $\begin{array}{l}\text { Cashflow untuk } \\
\text { menghitung } \\
\text { IRR }\end{array}$ & $\begin{array}{r}(275.796 . \\
000)\end{array}$ & -4.750 & 91.150 & 193.550 & 193.550 & 421.399 \\
\hline 5. & $\begin{array}{l}\text { Discount } \\
\text { Factor } 10 \%\end{array}$ & 10.000 & 0,909 & 0,826 & 0,751 & 0,683 & 0,621 \\
\hline
\end{tabular}




\begin{tabular}{llrrrrrr}
\hline \multirow{2}{*}{ 6. } & Present Value & $(275.796$. & 4.317 .75 & 75.289 .9 & 145.356. & 132.194. & 261.688. \\
& & $000)$ & 0 & 00 & 050 & 650 & 779 \\
\hline 7. & Commulative & $(275.796$. & $(280.113$. & $(204.823$ & $(59.467 .8$ & 72.726 .8 & 334.415. \\
& PV & $000)$ & $750)$ & $.850)$ & $00)$ & 50 & 629 \\
\hline 8. & Analisis Kelayakan Usaha & & & & & \\
\hline & NPV (Rp) & 334.415 .629 & & & & \\
\hline & IRR (\%) & $35,18 \%$ & & & & \\
\hline Net B/C Ratio & 2,19 & & & & & \\
\hline
\end{tabular}

Sumber: Data primer yang diolah, 2019.

Total cost yang dikeluarkan untuk usaha sarang burung walet selama produksi 5 tahun adalah sebesar Rp 344.046.000 yang berasal dari investasi awal yaitu sebesar Rp 275.796.000 dan biaya variabel sebesar Rp 12.000.000 serta biaya tetap sebesar Rp 56.250.000.

Penerimaan yang diperoleh dari usaha sarang burung walet ketika usaha berjalan selama 5 tahun sangat tinggi. Selengkapnya daftar harga sarang burung walet berdasarkan kualitasnya dapat dilihat pada Tabel 2 berikut.

Tabel 2. Harga Sarang Burung Walet

\begin{tabular}{clc}
\hline No. & \multicolumn{1}{c}{ Kualitas } & $\begin{array}{c}\text { Harga } \\
(\mathrm{Rp} / \mathrm{Kg})\end{array}$ \\
\hline 1. & Mangkok (A) & 14.000 .000 \\
2. & Sudut (B) & 12.000 .000 \\
3. & Patahan (C) & 11.000 .000 \\
\hline
\end{tabular}

Sumber: Data primer yang diolah, 2019.

Hasil produksi selama 5 tahun usaha sangat tinggi. Selengkapnya dapat dilihat pada Tabel 3 berikut.

Tabel 3. Produksi Sarang Walet (x000)

\begin{tabular}{ccccc}
\hline No. & $\begin{array}{c}\text { Produksi } \\
(\mathrm{Kg})\end{array}$ & $\begin{array}{c}\text { Jenis/ } \\
\text { Kualitas } \\
(\mathrm{A}, \mathrm{B}, \mathrm{C})\end{array}$ & $\begin{array}{c}\text { Harga } \\
(\mathrm{Rp})\end{array}$ & $\begin{array}{c}\text { Jumlah } \\
(\mathrm{Rp})\end{array}$ \\
\hline 1. & 0,5 & $\begin{array}{l}\text { Campur } \\
\text { (A,B, C) }\end{array}$ & $\begin{array}{c}13.00 \\
0\end{array}$ & 6.500 \\
2. & 8 & $\begin{array}{l}\text { Campur } \\
\text { (A,B, C) }\end{array}$ & $\begin{array}{c}13.00 \\
0\end{array}$ & 104.000 \\
3. & 16 & $\begin{array}{l}\text { Campur } \\
\text { (A,B, C) }\end{array}$ & $\begin{array}{c}13.00 \\
0\end{array}$ & 208.000 \\
4. & 16 & $\begin{array}{l}\text { Campur } \\
\text { (A,B, C) }\end{array}$ & $\begin{array}{c}13.00 \\
0\end{array}$ & 208.000 \\
5. & 20 & Campur & 13.00 & 260.000 \\
\hline
\end{tabular}

$(\mathrm{A}, \mathrm{B}, \mathrm{C}) \quad 0$

\begin{tabular}{lll} 
Total & 60.5 & 786.500 \\
\hline
\end{tabular}

Keterangan:

Kualitas A, adalah sarang mangkok (kualitas terbaik)

Kualitas B, adalah sarang sudut (kualitas sedang)

Kualitas C, adalah sarang patahan (kualitas jelek)

Sumber: Data primer yang diolah, 2019.

Bapak Suwaji menjual sarang burung walet dari semua kualitas dengan harga campuran antara A, B, dan C. Harga campuran sebesar $\mathrm{Rp} 13.000 .000$ per kilogram. Total penerimaan dari penjualan sarang burung walet selama 5 tahun produksi adalah sebesar Rp 786.500.000. Dengan demikian, keuntungan usaha sarang burung walet Bapak Suwaji yang telah dijalankan selama periode 5 tahun diperoleh keuntungan usaha sebagai berikut:

$$
\begin{aligned}
= & \mathrm{TR}-\mathrm{TC} \\
= & \mathrm{Rp} 786.500 .000-\mathrm{Rp} 344.046 .000 \\
= & \mathrm{Rp} 442.454 .000 \\
& \text { Jadi pada usaha sarang burung }
\end{aligned}
$$
walet Bapak Suwaji yang telah dijalankan selama 5 tahun, total memperoleh keuntungan usaha yang besar, yaitu sebesar $\mathrm{Rp}$ 442.454.000 atau dengan rata-rata memperoleh keuntungan sekitar Rp 88.490.000 per tahun. 


\section{Analisis Kelayakan}

\section{Net Present Value (NPV)}

NPV (Net Present Value) yang dihitung berdasarkan selisih antara nilai sekarang atas penerimaan yang diterima dikurangi dengan nilai sekarang atas biaya yang ditanggung selama masa usaha sarang burung walet berdasarkan diskon faktor sebesar 10\%. Sehingga dilakukan perhitungan maka diperoleh NPV sebesar Rp 334.415.629. Nilai NPV tersebut bernilai positif atau NPV > 0 , NPV (Net Present Value) yang bernilai positif artinya usaha sarang burung walet layak untuk dijalankan.

\section{Internal Rate of Return (IRR)}

Hasil perhitungan IRR Internal Rate of Return usaha sarang burung walet adalah 39,86\%. Nilai tersebut lebih besar dari suku bunga $10 \%$, karena nilai IRR lebih besar dari suku bunga maka usaha sarang burung walet dinyatakan layak atau memberikan manfaat selama umur proyek yang diperhitungkan. IRR yang dihitung adalah berdasarkan NPV 1 dan NPV 2 berdasarkan hasil percobaan dari asumsi dua diskon faktor yang kemudian diinterpolasi sehingga mendapatkan hasil sebesar $35,18 \%$.

\section{Internal Rate of Return (IRR)}

Net B/C Rasio pada usaha sarang burung walet ini didapatkan hasil sebesar 1,8 pada diskon faktor sebesar $10 \%$. Net B/C Rasio bernilai 2,19 atau Net B/C Rasio $>1$ yang artinya proyek atau usaha layak dijalankan/dilanjutkan secara finansial.

\section{Payback Period}

Payback Period menunjukkan kemampuan tingkat pengembalian usaha atau modal. Hasil perhitungan payback period pada usaha sarang burung walet Bapak Suwaji menunjukkan bahwa lamanya pengembalian modal investasi dalam waktu 4 tahun 4 bulan. Sesuai dengan Time Value of Money dimana semakin cepat jangka waktu pengembalian investasi atau semakin cepat penerimaan diraih menunjukkan bahwa usaha sarang burung walet Bapak Suwaji ini menguntungkan dan layak untuk diteruskan.

\section{Analisis Sensitivitas}

Penurunan produksi sarang burung walet sebesar 30 persen, dikarenakan faktor cuaca dan musim bertelur sehingga menyebabkan produksi sarang burung walet turun diperoleh hasil NPV (Net Present Value) sebesar Rp168.952.279;IRR sebesar 24,44\%; Net $\mathrm{B} / \mathrm{C}$ sebesar 1,59 dan payback period selama 5,7 tahun atau 5 tahun 8 bulan. Penurunan produksi sebesar $30 \%$ mengakibatkan penurunan NPV, Net B/C, IRR dan Payback Period lebih lama dari kondisi normal. Namun penurunan tersebut masih memberikan penilaian layak. Ini berarti bahwa usaha sarang burung walet masih menguntungkan walaupun produksi menurun $30 \%$ sampai pada tingkat suku bunga $24,44 \%$.

Penurunan harga jual sarang burung walet sebesar 20 persen, dikarenakan penurunan permintaan. Sehingga menyebabkan turunnya harga jual sarang burung walet diperoleh hasil NPV sebesar Rp 224.106.729; IRR sebesar 27,84\%; Net B/C sebesar 1,79 dan payback period selama 5,2 tahun atau 5 tahun 2 bulan. Turunnya harga sebesar $20 \%$ berpengaruh terhadap turunnya NPV, Net B/C, dan IRR, serta Payback Period. Meskipun mengalami penurunanNPV, Net $\mathrm{B} / \mathrm{C}$, dan IRR, usaha sarang burung walet masih layak untuk dilaksanakan.

\section{KESIMPULAN DAN SARAN}

\section{Kesimpulan}

1. Analisis kelayakan usaha sarang burung walet Bapak Suwaji selama periode produksi 5 tahun dimana arus kas menunjukkan total penerimaan sebesarRp 786.500.000, total biaya sebesarRp 344.046.000 dan penerimaan bersih sebesarRp 442.454.000. Pada analisis finansial berdasarkan penilaian 
kriteria investasi diskon faktor $10 \%$ didapatkan hasil perhitungan sebagai berikut, yaitu: 1) Nilai NPV > 0 yaitu sebesar Rp 334.415.629; 2) Nilai IRR > i yaitu sebesar $35,18 \%$; 3) Nilai Net $\mathrm{B} / \mathrm{C}>1$ yaitu sebesar 2,19; dan 4) Payback Period sebesar 4,4 tahun (4 tahun 4 bulan). Hasil penilaian menunjukkan bahwa usaha sarang burung walet Bapak Suwaji tersebut layak untuk dilaksanakan atau dilanjutkan, karena nilai NPV, IRR, Net B/C dan Pacback Period menunjukkan usaha tersebut menguntungkan serta selisih dari penerimaan dan biaya produksi yang relatif besar dan pengembalian investasi yang singkat yaitu terjadi pada 4,4 tahun atau hanya 4 tahun 4 bulan setelah usaha sarang burung walet berjalan.

2. Analisis sensitifitas usaha sarang burung walet Bapak Suwaji sensitif terhadap perubahan yang terjadi karena penurunan produksi dan penurunan harga jual sarang burung walet, maka didapatkan hasil sebagai berikut : a) Saat kondisi produksi sarang burung walet mengalami penurunan sebesar $30 \%$ diperoleh hasil sebagai berikut : 1) Nilai NPV > 0 yaitu sebesar Rp 168.952.279; 2) Nilai IRR > i yaitu sebesar 24,44\%; 3) Nilai Net B/C > 1 yaitu sebesar 1,59; dan 4) Payback Period selama 5,7 tahun atau selama 5 tahun 8 bulan. Saat kondisi penurunan harga jual sarang burung walet sebesar $20 \%$ diperoleh hasil sebagai berikut : 1) Nilai NPV > 0 Rp 224.106.729; 2) Nilai IRR > i yaitu 27,84\%; 3) Nilai Net B/C $>1$ yaitu 1,79 ; 4) Payback Period sebesar 5,2 tahun (5 tahun 2 bulan).

\section{Saran}

1. Pemilik usaha sarang burung walet, apabila terjadi pernurunan produksi sebesar 30\% maka disarankan kepada pemlik usaha agar tidak memanen sarang dengan cara membuang telur karena dapat menghambat populasi burung walet. Sebaiknya ditunggu hingga telur menetas dan burung terbang, setelah itu sarang dapat dipanen. Sedangkan ketika harga jual sarang turun sebesar $20 \%$ maka disarankan kepada pemilik usaha agar memanen sarang dengan cara panen pilihan atau memilih sarang yang tebal dengan kualitas terbaik agar harga jualnya tinggi.

2. Pemerintah dalam perannya sebagai lembaga penunjang agar untuk kedepannya dapat menurunkan besaran pajak sarang walet dan mempermudah perijinan dalam usaha sarang burung walet.

\section{DAFTAR PUSTAKA}

Budiman, A. (2007). Pedoman Membangun Gedung Walet. Jakarta: Agromedia Pustaka. (2008). Memproduksi Sarang Burung Walet Kualitas Atas. Jakarta: Swadaya.

Dinas Penanaman Modal dan Pelayanan Terbuka Satu Pintu Kabupaten Kotawaringin Timur. (2019). Pemilik Gedung Walet. Sampit. Dinas Penanaman Modal dan Pelayanan Terbuka Satu Pintu.

Gittinger, J. Price. (1986). Analisa Ekonomi Proyek-Proyek Pertanian. Jakarta: UI-Press dan John Hopkins.

Ibrahim, Y. (2003). Studi Kelayakan Bisnis. Jakarta: Rhineka Cipta.

Husein, Umar. (2009). Metode Penelitian Bisnis. Jakarta: Rajawali Persada.

Whiendrata, H.S. (2011). Jurus Jitu Budidaya Burung Walet. Yogyakarta: Lily Publisher. 